Article

\title{
Defrosting Performance Improvement of Air-Source Heat Pump Combined Refrigerant Direct-Condensation Radiant Floor Heating System with Phase Change Material
}

\author{
Chenxiao Zheng ${ }^{1}$, Shijun You ${ }^{1}$, Huan Zhang ${ }^{1}$, Zeqin Liu ${ }^{2}$, Wandong Zheng ${ }^{1, * \mathbb{D}}$, Zhenjing Wu ${ }^{1}$ \\ and Man Fan ${ }^{3}$ \\ 1 School of Environmental Science and Engineering, Tianjin University, Tianjin 300350, China; \\ zhengchenxiao2010@163.com (C.Z.); yousj@tju.edu.cn (S.Y.); zhhuan@tju.edu.cn (H.Z.); \\ wuzhenjing@tju.edu.cn (Z.W.) \\ 2 School of Mechanical Engineering, Tianjin University of Commerce, Tianjin 300134, China; liuzeqin@126.com \\ 3 School of Energy and Environmental Engineering, Hebei University of Technology, Tianjin 300401, China; \\ fanman@hebut.edu.cn \\ * Correspondence: wdzheng@tju.edu.cn
}

Received: 29 July 2020; Accepted: 28 August 2020; Published: 4 September 2020

check for updates

\begin{abstract}
Traditional defrosting methods applied to solve frosting problems of air-source heat pumps operating in cold periods may reduce heat capacity of the system and decrease indoor thermal comfort. In order to improve the performance of air-source heat pump (ASHP) and maintain indoor temperature in defrosting conditions, an air-source heat pump combined with a refrigerant direct-condensation radiant floor heating system with phase change material is proposed and evaluated in this study. Two radiant floor heating terminals with and without composite phase change material modules were compared through experiments. A composite phase change material based on dodecanoic acid-tetradecanol-hexadecanol mixture and expanded graphite was investigated for this application. Experimental results indicate that both heat fluxes of two comparing terminals are higher than $70 \mathrm{~W} / \mathrm{m}^{2}$ in heating condition. At the same time, the floor surface temperature, indoor air temperature, and heating capacity of the terminal with composite phase change material modules are higher than those without composite phase change material modules in defrosting condition. This suggests that the proposed system with composite phase change material modules can improve indoor thermal comfort in defrosting condition as well as satisfy the heating requirement in heating condition.
\end{abstract}

Keywords: ASHP system; refrigerant direct-condensation radiant floor heating; CPCM; defrosting; indoor thermal comfort

\section{Introduction}

With the energy shortage and environmental deterioration, the air-source heat pump (ASHP) has been used worldwide instead of consumption of fossil fuels for space heating [1]. The ASHP systems are gaining increasing attention owing to the advantages of energy-saving, flexibility, and environmental friendliness, and are available to supply cooling and heating for residential and commercial buildings [2]. However, a fan coil unit is the traditional heating terminal of the ASHP system, which may generate strong draft sensation and affect the comfort and health of occupants [3]. At the same time, the ASHP system experiences the frosting problem of the outdoor evaporator when operating in severe cold regions, thereby causing the decrease of indoor temperature [4].

The heating terminals could be categorized into two main types: fan coils and radiant heating terminals. Compared with the fan coils system, the radiant heating system could not only avoid 
occupants discomfort caused by the generated strong draft sensation but also utilize the low-grade energy [5,6]. Radiant heating terminals have been experimentally and numerically investigated, mainly including the radiator and radiant floor [7]. Radiator is the most common heating terminal used in residential heating system, and its heat transfer process, power consumption, and room comfort have been studied by many researches [8-11]. However, compared with the radiator system, radiant floor heating system has a higher uniform temperature profile in vertical direction, lower energy consumption, and lower $\mathrm{CO}_{2}$ emissions [12]. In addition, radiant floor heating system could create higher indoor thermal comfort by maintaining a higher temperature of the foot region with the same supply temperature, and avoid overheating problems $[13,14]$. Furthermore, considerable researches on the parameters of radiant floor heating systems have been reported. Sattari and Farhanieh [15] numerically studied design parameters of a typical radiant floor heating system, such as the diameter, material, and number of heating pipe and the type and thickness of the cover, all affecting the performance of the system, especially the type and thickness of the cover. After that, Shin et al. [16] studied the relationships between heat flux and parameters of radiant floor heating system and developed design charts. Li et al. [17] proposed an analytical calculation method to analyze the thermal performance of a multilayer radiant floor and validated the method by experiments. $\mathrm{Xu}$ et al. [18] developed a radiant floor heating without water, fed by ASHP-integrated solar, and studied the feasibility of the system by experiment. Above all, in order to improve indoor thermal environment of heat pump heating system, the radiant floor heating terminal could be combined with a heat pump because of its applicability and high indoor thermal comfort.

To solve the above frosting problem, the frosting characteristics and defrosting methods including refrigerant reverse cycle and hot gas bypass have been applied [19], while these methods result in the deterioration of the indoor thermal comfort [20]. Accordingly, thermal energy storage technology—especially phase change material (PCM) —is applied to improve the performance of ASHP system in defrosting condition [21]. Daikin Industries Ltd. [22] applied the latent thermal energy storage technology into the heat pump for defrosting to recycle the heat released by the compressor and reuse it for defrosting. The heating capacity and coefficient of performance (COP) of the system were improved by $10 \%$ and $50 \%$, respectively. Chen et al. [23] added an indirect heat-storage system in an air-source-cooling and hot-water-supplying unit to store heat in a PCM heat exchanger in heating condition and then release the heat to heat the cycling water in defrosting condition. Dong et al. [24] installed a PCM heat exchanger between the indoor heat exchanger and capillary, which was a heat source in defrosting condition instead of indoor air. After that, Zhang et al. [25] and Dong et al. [26] utilized PCM heat exchangers added in a traditional ASHP system and multisplit ASHP system to store thermal energy in heating conditions and release for defrosting, respectively. Ma et al. [27] added a PCM evaporator to ASHP system to absorb heat through one heat exchanger pipe in heating condition and release heat through another heat exchanger pipe in defrosting condition. Qu et al. [28] added a PCM heat exchanger to improve the defrosting problem of cascade heat pump system used in cold area. Liu et al. [29] developed a new PCM heat exchanger used in ASHP system, there were two defrosting modes that could be selected because of two heat exchanger pipes which were set in the PCM heat exchanger. The results indicated that the performance of experimental systems with PCM heat exchangers was improved and the energy consumption was decreased. However, PCM heat exchanger has been added to ASHP system to store heat in heating condition and provide for defrosting in most existing researches, which increased system complexity.

In order to avoid system complexity and improve the indoor thermal comfort, PCM could be installed in radiant floor terminal instead of adding another heat exchanger in the system. Cabrol and Rowley [30] made a transient simulation study on the characteristics of a PCM-embedded floor heating system combined with ASHP applied in high-performance building. The results indicated that the temperature stability could be improved by the PCM-embedded floor during heating season. Mazo et al. [31] developed a simulation model of the radiant floor system with PCM fed by a heat pump, the simulation results showed that the energy consumption reduced nearly $18 \%$ compared with the 
conventional case. Different heat storage materials were used in the radiant floor heating system and the performance were analyzed through a series of experiments by Zhou et al. [8]. Jin and Zhang [32] carried out a floor system including double layer PCM with different melting temperatures and the results showed that the energy released by the floor with PCM in peak period would be increased by $41.1 \%$ than floor without PCM during heating when the heat of fusion of the PCM was $150 \mathrm{~kJ} / \mathrm{kg}$. However, PCM was applied into the radiant floor to reduce operating fee and improve the stability of indoor temperature during the heating season excluding defrosting condition in those researches. Few studies have been carried on the performance of radiant floor heating system combined with PCM fed by ASHP, and even less in defrosting condition.

In this study, a novel ASHP system combined refrigerant direct-condensation radiant floor heating attached to thermal energy storage technology is proposed in order to retain the temperature of floor surface in defrosting condition without an additional PCM heat exchanger. The dodecanoic acid-tetradecanol-hexadecanol (LA-TD-HD) mixture as PCM and expanded graphite (EG) as supporting material are introduced in the terminal. The optimized composition and thermal properties of the composite phase change material (CPCM) are tested and investigated. Thereafter, the performance of proposed system in heating and defrosting conditions are experimentally studied through comprehensive comparison with the system without CPCM modules.

\section{Experimental Investigation}

\subsection{Thermal Performance of Energy Storage Material}

The phase change energy storage material used in the experimental system is organic compounds of dodecanoic acid (LA), tetradecanol (TD), and hexadecanol (HD); which is then absorbed by expanded graphite (EG). Dodecanoic acid (LA, AR), tetradecanol (TD, AR), and hexadecanol (HD, AR) are purchased from Real \& Lead Chemical Ltd., Tianjin China. Expansible graphite (expansion coefficient: $600 \mathrm{~mL} / \mathrm{g}$, Carbon content: 99.9\%) is supplied by Yanhai Carbon Materials Ltd., Qingdao China.

To investigate the thermal properties of the PCMs, specific parameters of LA, TD, HD, and LA-TD-HD mixture are tested by differential scanning calorimetry (DSC; Q 2000, TA, USA). In this test, 3-5 mg testing samples of LA, TD, HD, and LA-TD-HD mixture are put in aluminum pans. At the same time, the heating and cooling rate of the measurement is set at $10^{\circ} \mathrm{C} \cdot \mathrm{min}^{-1}$ under a nitrogen atmosphere. Furthermore, the flow rate of nitrogen is $50.0 \mathrm{~mL} / \mathrm{min}$. The accuracy of the calorimeter in DSC is within $\pm 1 \%$.

To promote the melted PCM from leak, many solutions have been proposed, such as EG, encapsulation, and so on. Compared with other solutions, EG has high thermal conductivity, excellent chemical stability, cost-effective price, high specific surface area, and low density; which can reduce cost, avoid limit of corrosion, and avoid load-bearing. To promote the thermal conductivity of the CPCM and prevent the melted PCM from leaking [33-36], EG is mixed to absorb the phase transformation solution. In order to investigate the effect of EG on the heat transfer behavior of LA-TD-HD mixture, the heat storage and release performances of the LA-TD-HD mixture and LA-TD-HD/EG CPCM are tested. An amount of $10 \mathrm{~g}$ of the PCM and its CPCM (absorbed by EG) are put into test tubes. Then, a temperature sensor $\left(\mathrm{PT} 100, \pm 0.1^{\circ} \mathrm{C}\right.$ ) is installed in each test tube to monitor the temperature variations of two samples during the phase change process. Subsequently, two test tubes are placed in environment with a constant temperature of $18.5^{\circ} \mathrm{C}$. In the heat storage process, samples in two test tubes are cooled down, and the test tubes are moved into the water bath with a constant temperature of $37.5^{\circ} \mathrm{C}$ when their temperature reached stable states. Meanwhile, in the heat release process, the test tubes are moved to the environment with a constant temperature of $18{ }^{\circ} \mathrm{C}$ after the heat storage process competed. The monitored data is collected by the data acquisition unit with an interval of $1 \mathrm{~s}$. 


\subsection{Experimental Setup of the Proposed System}

\subsubsection{Experimental Platform of the Proposed System}

The schematic of the novel system is depicted in Figure 1. The experimental system is made up of a compressor, a four-way valve, a gas-liquid separator, an outdoor coil, an accumulator, a thermostatic expansion valve, four solenoid valves, and the proposed radiant floor heating terminal. Figures 2 and 3 are the structure and photographs of the experimental heating terminal, respectively.

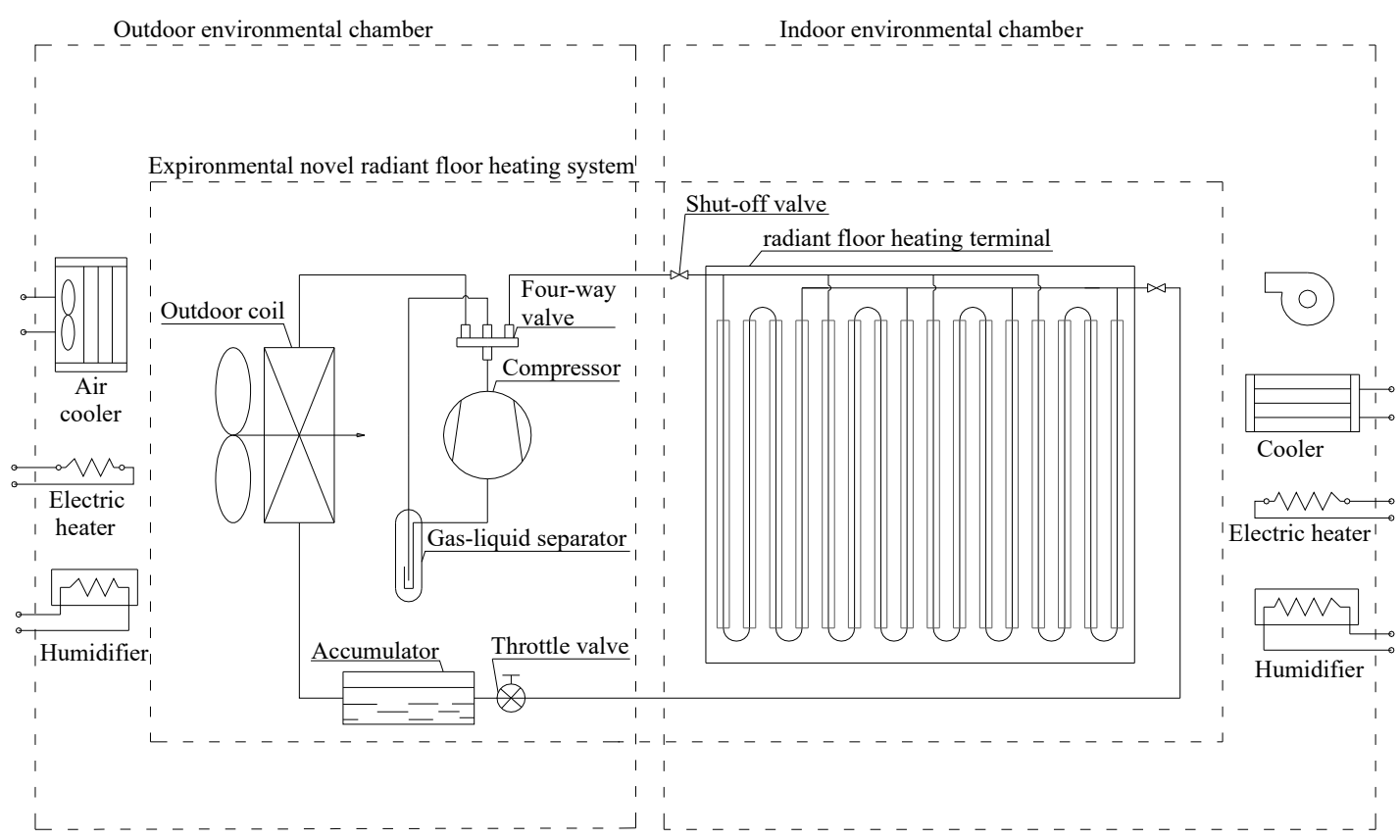

Figure 1. Schematic of the experimental platform and the novel air-source heat pump (ASHP) heating system.

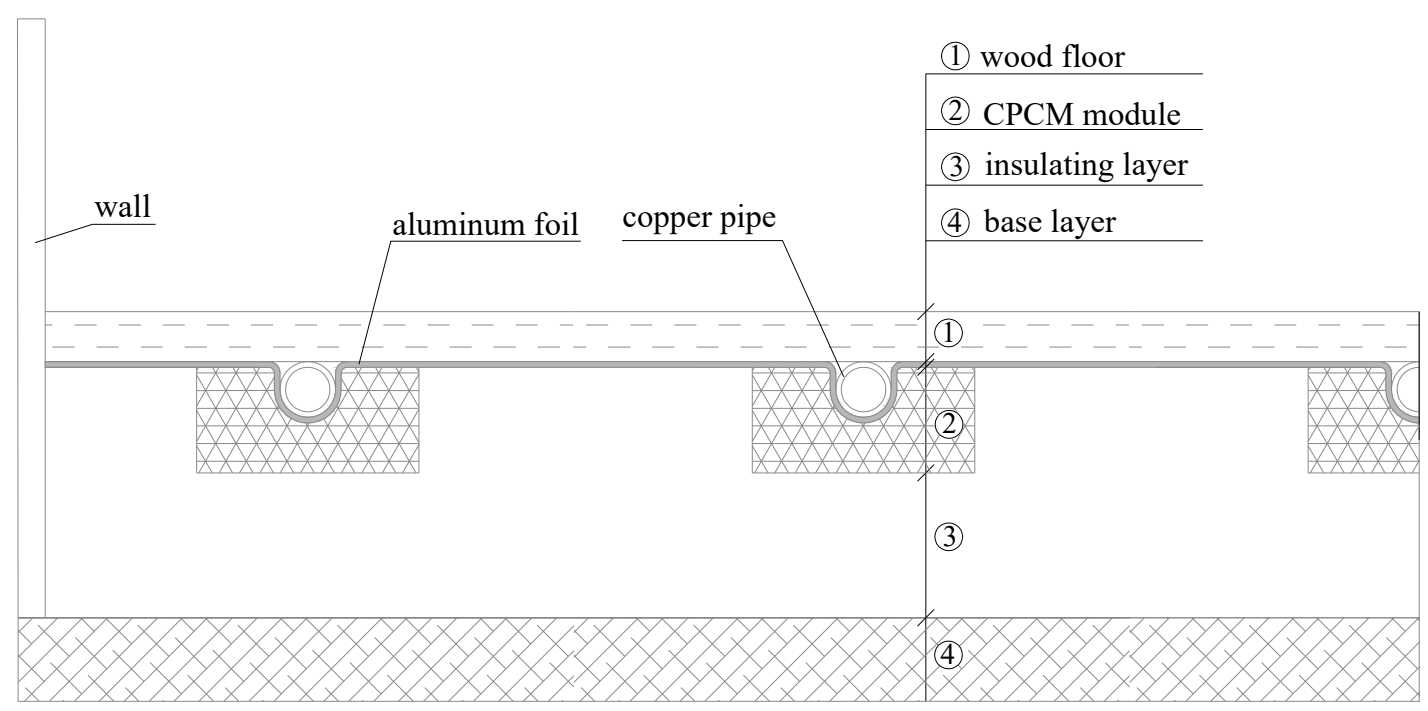

Figure 2. Structure of the radiant floor heating terminal with composite phase change material (CPCM) modules. 

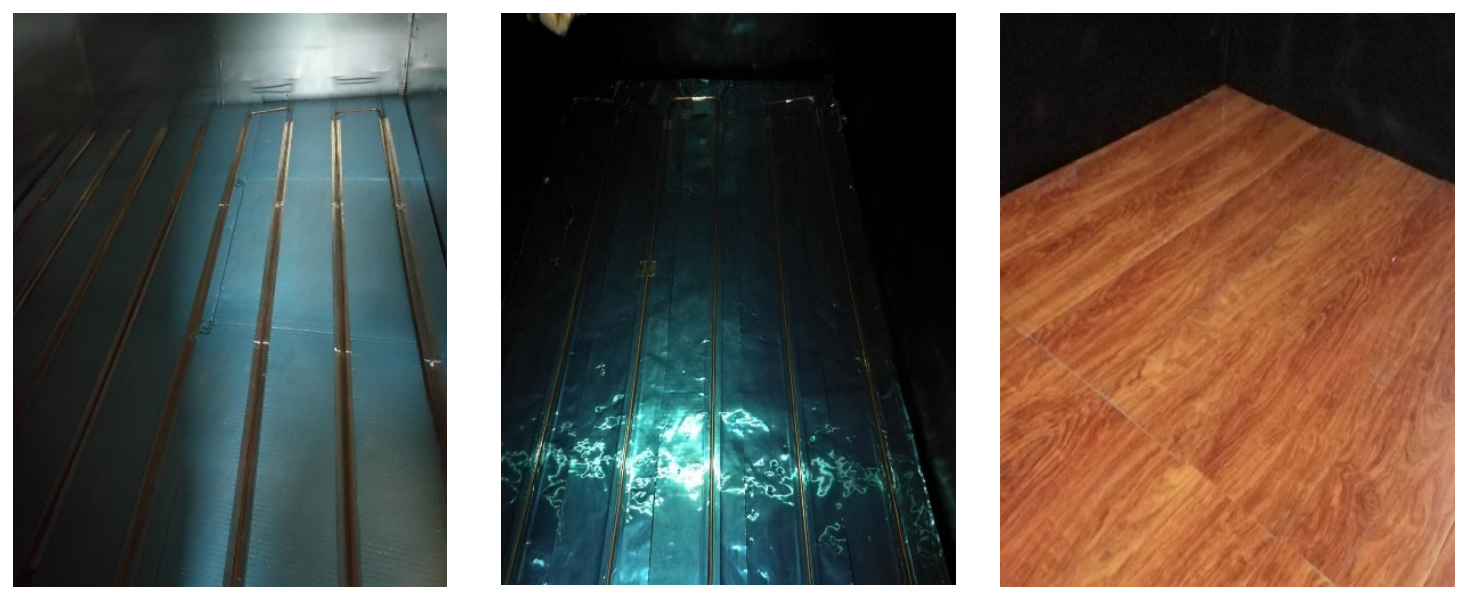

Figure 3. Photographs of the experimental heating terminal structure.

As shown in Figure 1, the platform consists of an outdoor environmental chamber, an indoor environmental chamber, and a proposed radiant floor heating terminal fed by ASHP. The sizes of the outdoor environmental chamber and indoor environmental chamber are $3000 \times 1500 \times 1200 \mathrm{~mm}$ (Length $\times$ Width $\times$ Height) and $1900 \times 1900 \times 2000 \mathrm{~mm}$ (Length $\times$ Width $\times$ Height), respectively. To provide specific experimental conditions, an air-cooling unit, electric heater, and humidifier are installed in the outdoor environmental chamber. At the same time, the temperature and humidity of the indoor environmental chamber are controlled by another air conditioning system. To satisfy the experimental requirement of indoor thermal environment, the air conditioning system consists of a cooler, a supply fan, a humidifier, and an electric heater. Furthermore, a proportion-integration-differentiation controller is installed in the indoor environmental chamber. In addition, the wall surfaces of the indoor room are coated with flat paint, and the emissivity of floor and wall surfaces are 0.87 and 0.9 , respectively.

The terminal is composed of floor, copper pipes, CPCM modules, aluminum foil, and insulating layer. The thicknesses of floor, aluminum foil, and insulating layer are $8 \mathrm{~mm}, 0.2 \mathrm{~mm}$, and $50 \mathrm{~mm}$, respectively. The outside diameter and thickness of the tubes in the experiment are $6.35 \mathrm{~mm}$ and $0.5 \mathrm{~mm}$, respectively. The distance between copper pipes is $200 \mathrm{~mm}$. The aluminum foil is laid between the floor and insulating layer. The CPCM modules are installed under the straight pipe section of the heating coil. The copper pipes are wrapped by the aluminum foil and then embedded in the aluminum case tightly. At the same time, the copper pipes contact with the floor and the aluminum foil simultaneously, as shown in Figures 2 and 3. The CPCM modules consist of LA-TD-HD/EG CPCM and aluminum case. The isometric diagram and sectional diagram of the CPCM module are shown in Figure 4a,b, respectively. As shown in Figure 4, LA-TD-HD/EG CPCM is encased in the aluminum case with a size of $500 \times 15 \times 20 \mathrm{~mm}$ (Length $\times$ Width $\times$ Height). The material and thickness of the encapsulation case are aluminum and $0.5 \mathrm{~mm}$, respectively. The insulating layer and base layer defined in Figure 2 are extruded polystyrene board and floor slab, respectively. In addition, the heating medium is refrigerant, which transfers heat from the heat pump to the indoor environment. In heating condition, the heat from refrigerant passes through the copper pipes and transfers to the floor and aluminum foil, then heats the indoor air and CPCM modules simultaneously. In the defrosting condition, the thermal energy stored in the CPCM modules is simultaneously released to heat refrigerant and indoor air. 


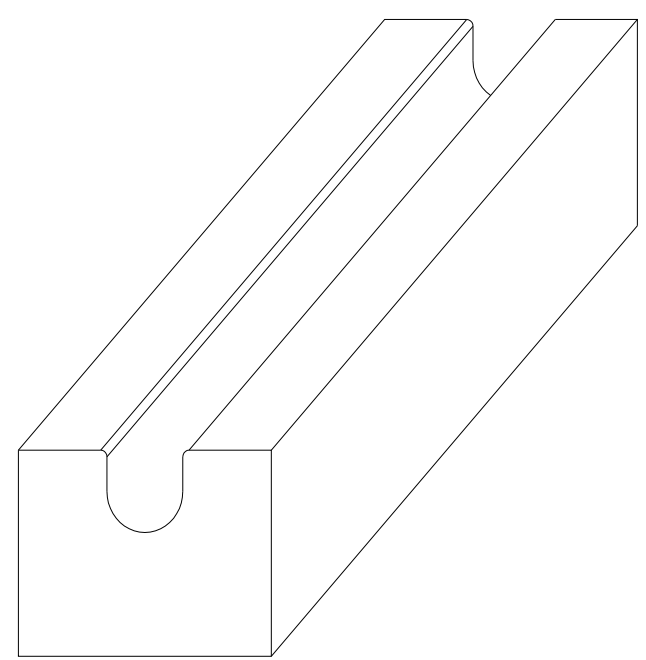

(a) Isometric diagram of the CPCM module aluminum case

LA-TD-HD/EG CPCM

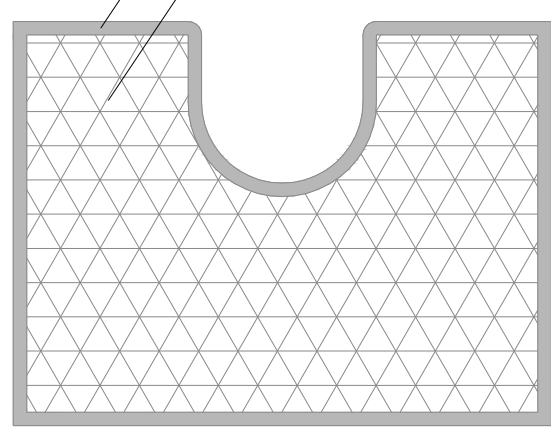

(b) Sectional diagram of the CPCM module

Figure 4. Structure of the CPCM modules in the radiant floor heating terminal.

\subsubsection{Measuring Instruments}

Figure 5 shows layout of testing points in the indoor environmental chamber [37]. Five temperature testing points are set on the floor surface, and the average value of these five testing points is considered as the surface temperature of the radiant floor [38]. There are temperature testing points arranged at the center of the walls and ceiling, and the average value of them is considered as the surface temperature of the unheated wall. To measure the air temperature in the indoor environmental chamber, a testing point is located at the center point of $0.75 \mathrm{~m}$ height level from the floor surface [37].

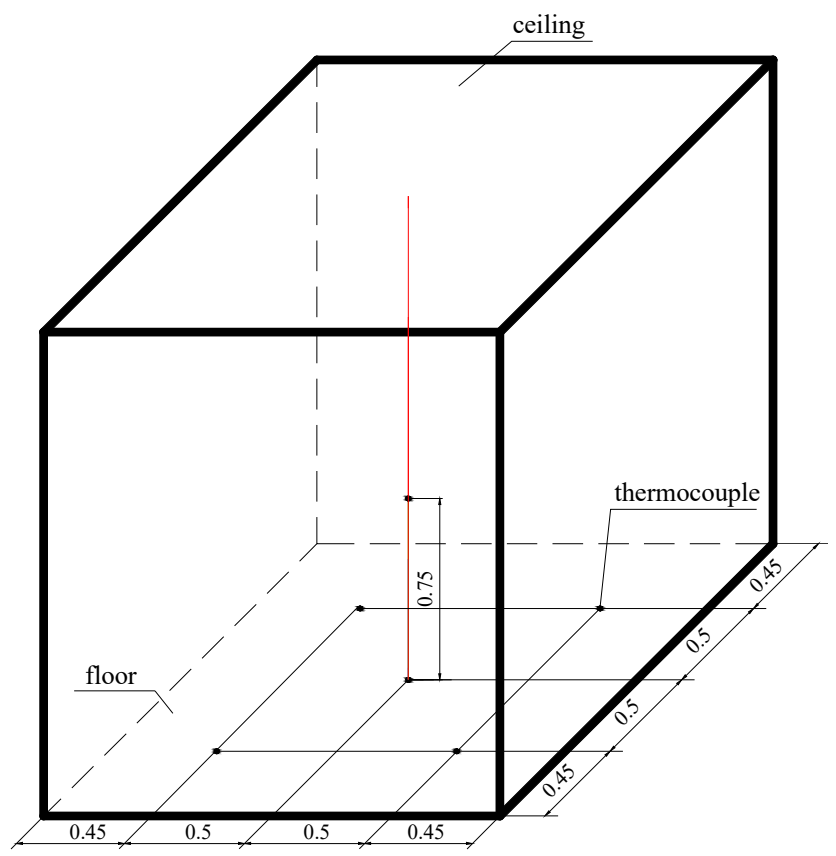

Figure 5. Layout diagrams of the measurement locations in the indoor environmental chamber.

In addition, the temperatures of outdoor air, inlet, and outlet of the indoor environmental chamber air-conditioning system are measured in the experiment. The relative humidity of the indoor and outdoor environmental chambers are measured at the same time. The air temperature and humidity in the experiment are measured by temperature sensor (PT100) with an accuracy of $\pm 0.1^{\circ} \mathrm{C}$ and humidity 
sensors with an accuracy of $\pm 2.5 \%$, respectively. The temperature of wall surfaces are measured by thermocouples with an accuracy of $\pm 0.5{ }^{\circ} \mathrm{C}$. At the same time, the temperature sensors in the indoor room are shielded from radiant. All the monitored data is collected by the data acquisition units with an interval of $1 \mathrm{~s}$.

\subsubsection{Experimental Procedures}

Firstly, the air temperature and relative humidity of the outdoor environmental chamber are maintained at $-3 \pm 0.5^{\circ} \mathrm{C}$ and $79.0 \% \pm 2.5 \%$, respectively [39]. Then, operating characteristics and heating performance of the proposed radiant floor heating terminal fed by ASHP system are tested under heating and defrosting conditions.

When starting the heating experiment, the compressor and outdoor coil fan are switched on first. The refrigerant is compressed and sent to the indoor radiant floor heating terminal. Then, the refrigerant is throttled and evaporated by the thermostatic expansion valve and the outdoor coil, respectively. Finally, the refrigerant flows back into the compressor and repeats the procedures above. The whole heating period is finished after the indoor air temperature comes into a steady state.

In this paper, the defrosting experiment is divided into defrosting period and reheating period by considering the time delay of the temperature variations. At the end of the heating experiment above, the defrosting experiment starts after the four-way valve is reversed. The compressed refrigerant is sent into the outdoor coil to provide heat for defrosting. Afterwards, the refrigerant is throttled by the thermostatic expansion valve and evaporated by the energy stored in the radiant floor heating terminal. The refrigerant flows back to the compressor finally. The defrosting period is terminated at the 7.5th minute when the frost on the outdoor coil is all melted. Then, the four-way valve is reversed, and the system resumes heating condition. The heating process finishes until the indoor air temperature starts rising, which is named as the reheating period.

\subsubsection{Data Reductions and Uncertainty Analysis}

The heating capacity transferred from the radiant floor terminal into the room $Q$ and the heat flux of the radiant floor terminal $q$ can be calculated by Equations (1) and (2), respectively [6].

$$
\begin{gathered}
Q=h_{c} A\left(t_{f}-t_{a}\right)+h_{r} A\left(t_{f}-t_{w}\right), \\
q=\frac{Q}{A},
\end{gathered}
$$

where $h_{c}$ and $h_{r}$ are the convective heat coefficient and radiant heat transfer coefficient of the radiant floor surface, respectively. $A$ is the radiant floor surface area; $t_{f}, t_{a}$, and $t_{w}$ are radiant floor surface temperature, indoor air temperature, and unheated wall temperature, respectively. In addition, $h_{c}$ and $h_{r}$ are calculated by the following correlations according to recommendations in references [6,38,40-43].

$$
\begin{gathered}
h_{c}=N u \lambda / l, \\
h_{r}=\varepsilon \sigma\left[\left(t_{f}+273.15\right)^{2}+\left(t_{w}+273.15\right)^{2}\right]\left[\left(t_{f}+273.15\right)+\left(t_{w}+273.15\right)\right], \\
N u=0.15 R a^{\frac{1}{3}} \\
R a=G r P r \\
G r=\frac{g \beta\left(t_{f}-t_{a}\right) l^{3}}{v^{2}}, \\
\beta=\frac{1}{\left(t_{f}+t_{a}\right) / 2+273.15},
\end{gathered}
$$




$$
\operatorname{Pr}=\frac{v}{a}
$$

where $\mathrm{Nu}, \mathrm{Ra}, \mathrm{Gr}$, and $\mathrm{Pr}$ are the Nusselt number, Rayleigh number, Grashof number, and Prandtl number, respectively. $v, \lambda$, and $a$ are the kinematic viscosity, thermal conductivity, and thermal diffusivity of air, respectively. $l$ is the characteristic length, $\beta$ is the coefficient of volumetric expansion, $\varepsilon$ is the emissivity of the radiant floor surface, and $\sigma$ is the Stefan-Boltzmann constant $\left(5.67 \times 10^{-8} \mathrm{~W} \mathrm{~m}^{-2} \mathrm{~K}^{-4}\right)$.

In defrosting condition, the heat capacity of radiant floor heating terminal $Q$ is the sum of the sensible heat capacity $Q_{s}$ and the latent heat capacity $Q_{l}$ of the radiant floor heating terminal, as shown in Equation (10). In addition, the latent heat capacity $Q_{l}$ of the radiant floor heating terminal without CPCM modules is 0 .

$$
Q=Q_{s}+Q_{l}
$$

The primary parameters are obtained by the respective calibrated instruments. The uncertainty of the derived quantities can be calculated by Equation (11) [41]:

$$
\delta Y=\left[\sum_{i=1}^{n}\left(\frac{\partial Y}{\partial X_{i}} \partial X_{i}\right)^{2}\right]^{\frac{1}{2}}
$$

where $\delta Y$ is the uncertainty of the derived quantity $Y$, and $\delta X_{i}$ is the uncertainty of the primary parameter $X_{i}$. The uncertainties of the heating capacity transferred from the radiant floor terminal into the room is $3.1 \%$.

\section{Results and Discussion}

\subsection{Mass Ratio and Thermal Properties of LA-TH-HD Ternary Eutectic Mixture}

Phase change temperature is an important factor of PCM. Binary and ternary eutectic mixtures are made out to expand the application of PCM by reducing the phase change temperature [44,45]. The PCM in the experimental system is the eutectic organic compounds of LA, TD, and HD. The theoretical mass ratio and the phase change temperature of the eutectic mixture can be calculated by Equation (12) [45]. The specific parameters and mass percentages for three components of the mixture are listed in Table 1.

$$
T_{m}=\left[\frac{1}{T_{j}}-\frac{R \ln M_{j}}{H_{j}}\right]^{-1},
$$

where $T_{m}$ is the phase change temperature of the eutectic mixture; $R$ is the gas constant; $T_{j}, H_{j}$,

\begin{tabular}{|c|c|c|c|c|}
\hline \multirow{2}{*}{ PCM } & \multirow{2}{*}{$\begin{array}{l}\text { Latent Heat of Melting } \\
(\mathrm{J} / \mathrm{g})\end{array}$} & \multicolumn{2}{|c|}{ Melting Point $\left({ }^{\circ} \mathrm{C}\right)$} & \multirow{2}{*}{$\begin{array}{c}\text { Mass Percentage } \\
(\%)\end{array}$} \\
\hline & & Measured Value & Predicted Value & \\
\hline LA & 193.6 & 43.6 & - & 35.6 \\
\hline TD & 257 & 37.6 & - & 43.3 \\
\hline HD & 276 & 48.9 & - & 21.1 \\
\hline LA-TD-HD & 181.3 & 26.1 & 25.8 & 100 \\
\hline
\end{tabular}
and $M_{j}$ are the phase change temperature, latent heat, and molar fraction of the $j$ th component in the mixture, respectively.

Table 1. Specific parameters and mass percentages for LA, TD, and HD of phase change materials.

\subsection{The Optimum Mass Ratio of LA-TD-HD to EG}

Generally, latent heat of PCM is a key factor of its thermal energy storage ability. In the CPCM, only the LA-TD-HD PCM can absorb and release heat during phase change process, then the latent heat capacity of the CPCM is proportional to the content of LA-TD-HD PCM [44]. The latent heat of 
CPCM can be calculated by Equation (13) [44]. The latent heat of different mass fraction of EG with $0 \%$, $1 \%, 2 \%, 3 \%, 4 \%, 5 \%$, and $6 \%$ are listed in Table 2 .

$$
\Delta H_{C P C M}=\Delta H_{P C M} \times \frac{m_{P C M}}{m_{C P C M}}
$$

where $\triangle H_{C P C M}$ and $\triangle H_{P C M}$ are the latent heats of LA-TD-HD/EG CPCM and LA-TD-HD PCM, $m_{C P C M}$ and $m_{P C M}$ are the mass fractions of LA-TD-HD/EG CPCM and LA-TD-HD PCM, respectively.

Table 2. The latent heats of LA-TD-HD/EG CPCMs with different mass fraction of expanded graphite (EG).

\begin{tabular}{cccccccc}
\hline Mass fraction of EG $(\%)$ & 0 & 1 & 2 & 3 & 4 & 5 & 6 \\
\hline Latent heat $(\mathrm{J} / \mathrm{g})$ & 181.3 & 179.5 & 177.7 & 175.9 & 174.0 & 172.2 & 170.4 \\
\hline
\end{tabular}

To determine the optimum absorption ratio of the LA-TD-HD mixture to EG, the mass fraction of EG with $1 \%, 2 \%, 3 \%, 4 \%, 5 \%$, and $6 \%$ are prepared to investigate the absorption rate of the LA-TD-HD mixture in the filter paper [44,46]. As shown in Figure 6a, the prepared LA-TD-HD/EG CPCM samples are placed on the filter papers. Then, the prepared samples are heated at $35^{\circ} \mathrm{C}$ for $1 \mathrm{~h}$ and the state of samples after heat treatment is shown in Figure 6b. It can be seen from Figure $6 \mathrm{~b}$ that imprints appear on the filter papers when the mass fraction of LA-TD-HD/EG CPCM with EG are 1\% to $4 \%$ after heat treatment, which illustrate there is liquid LA-TD-HD PCM leakage from the samples. Therefore, the results indicate that the LA-TD-HD mixture cannot be adsorbed completely by EG when the mass fraction is less than $5 \%$. Given both the above results and the latent heat of the LA-TD-HD/EG CPCM, the optimal mass fraction of LA-TD-HD/EG CPCM with EG is determined as $5 \%$.

\subsection{Heat Storage and Release Performance of $L A-T D-H D$ and Its $C P C M$}

Heat storage and release rate of PCM are crucial indicators that can reflect heat storage and release performances. Figure 7 shows the storage and release performances of the LA-TD-HD and its CPCM. It is seen that the storage time for the temperature increasing from $18.5^{\circ} \mathrm{C}$ to $37.5^{\circ} \mathrm{C}$ is $17 \mathrm{~min}$ for the LA-TD-HD/EG CPCM, while it is $39 \mathrm{~min}$ for the LA-TD-HD PCM. Besides, the release time for the temperature decreasing from $37.5^{\circ} \mathrm{C}$ to $18^{\circ} \mathrm{C}$ is $65 \mathrm{~min}$ for the LA-TD-HD/EG CPCM, while it is $108 \mathrm{~min}$ for the PCM. Therefore, compared to the LA-TD-HD PCM, the storage and release time of its CPCM are reduced by $56.4 \%$ and $39.8 \%$, respectively. Obviously, the heat transfer rate of the LA-TD-HD/EG CPCM is significantly improved because of the addition of EG. Meanwhile, the heat storage capacity of the LA-TD-HD/EG CPCM sample and LA-TD-HD PCM sample are $1722 \mathrm{~J}$ and $1813 \mathrm{~J}$ according to their latent heats. The heat capacity of the LA-TH-HD/EG sample is slightly lower than that of the later one due to less addition of EG.

\subsection{Thermal Performance of the Experimental System in Heating Condition}

Figure 8 shows the temperature variations of floor surface and indoor air with and without CPCM modules in the steady state of heating condition. As depicted in this figure, both the temperature of radiant floor surface with and without $\mathrm{CPCM}$ modules are higher than $26.0^{\circ} \mathrm{C}$ in the steady state of heating condition. At the same time, both the indoor air temperature with and without CPCM modules are higher than $19.0^{\circ} \mathrm{C}$ in this period. Figure 9 shows the heating capacity variations of radiant floor heating terminal with and without CPCM modules in the steady state of heating condition. As shown in Figure 9, the heating capacity transferred into the room from radiant floor surface with and without CPCM modules is almost equal to each other. The average heat flux of radiant floor terminal with and without CPCM modules are $71.6 \mathrm{~W} / \mathrm{m}^{2}$ and $71.2 \mathrm{~W} / \mathrm{m}^{2}$, respectively. The above results indicate that the proposed system can satisfy the heating requirement with appropriate floor surface temperature and enough heating capacity. 


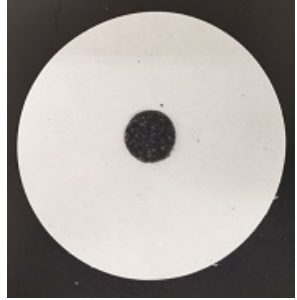

$1 \%$

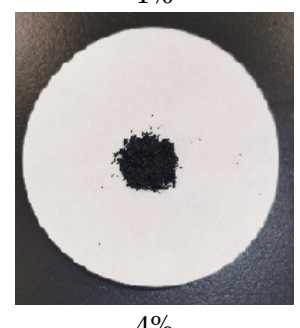

$4 \%$
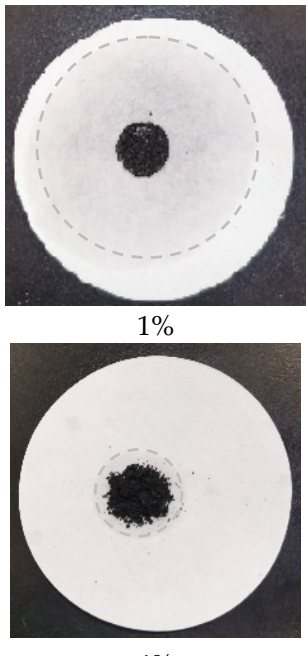

$4 \%$

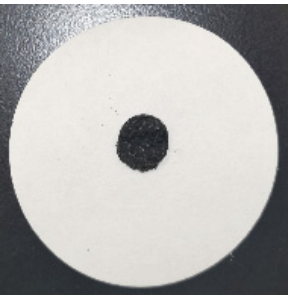

$2 \%$

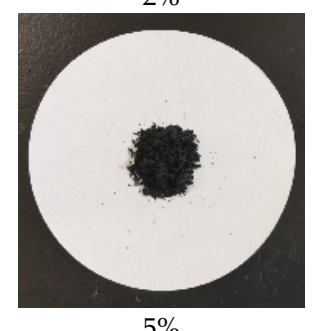

(a)
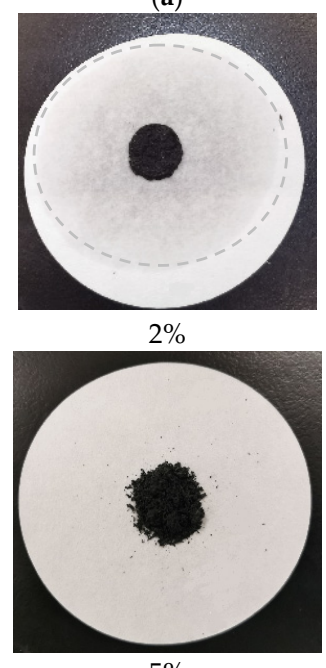

(b)

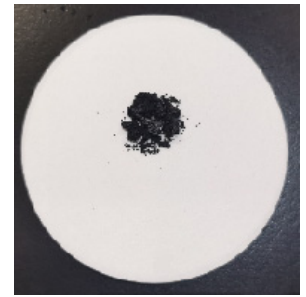

$3 \%$
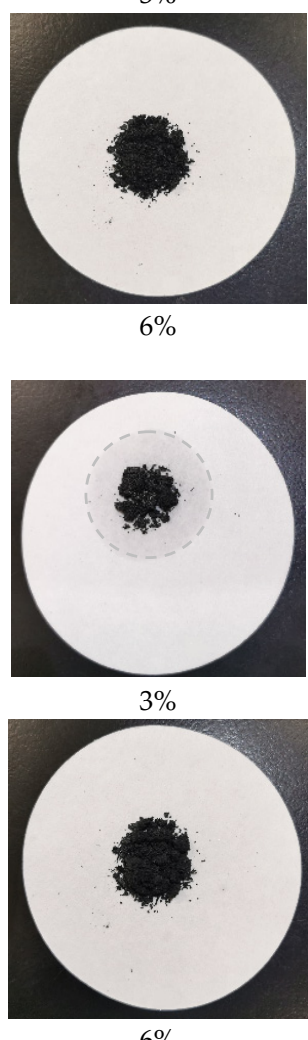

$6 \%$

Figure 6. Photographs of the CPCM (a) before and (b) after the thermal treatment.

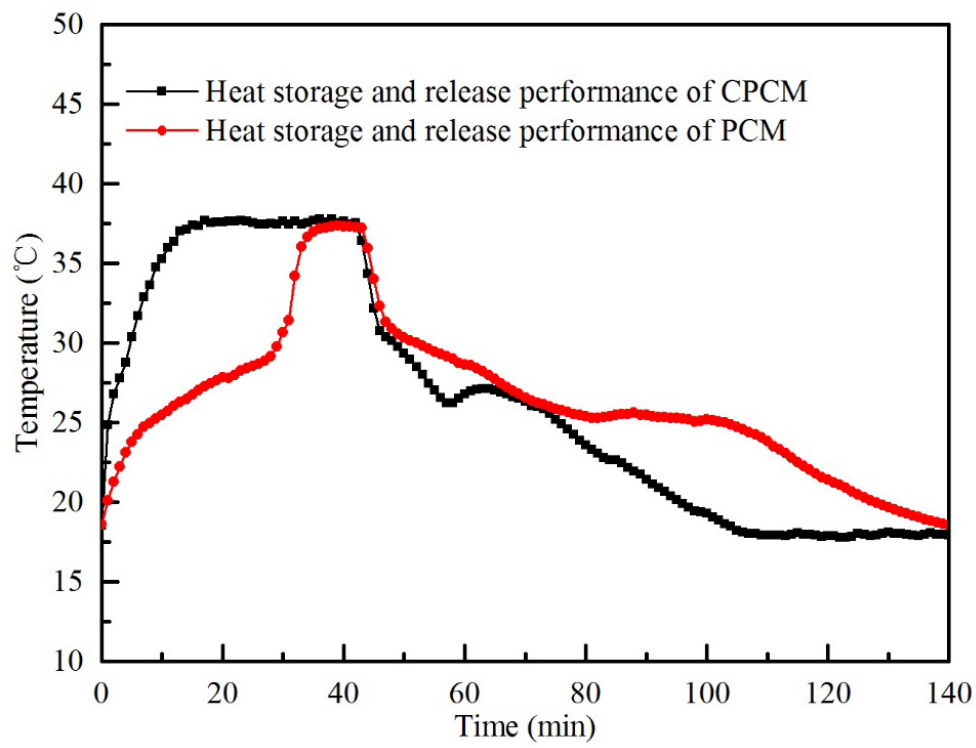

Figure 7. The heat storage and release performances of the phase change material (PCM) and its CPCM. 


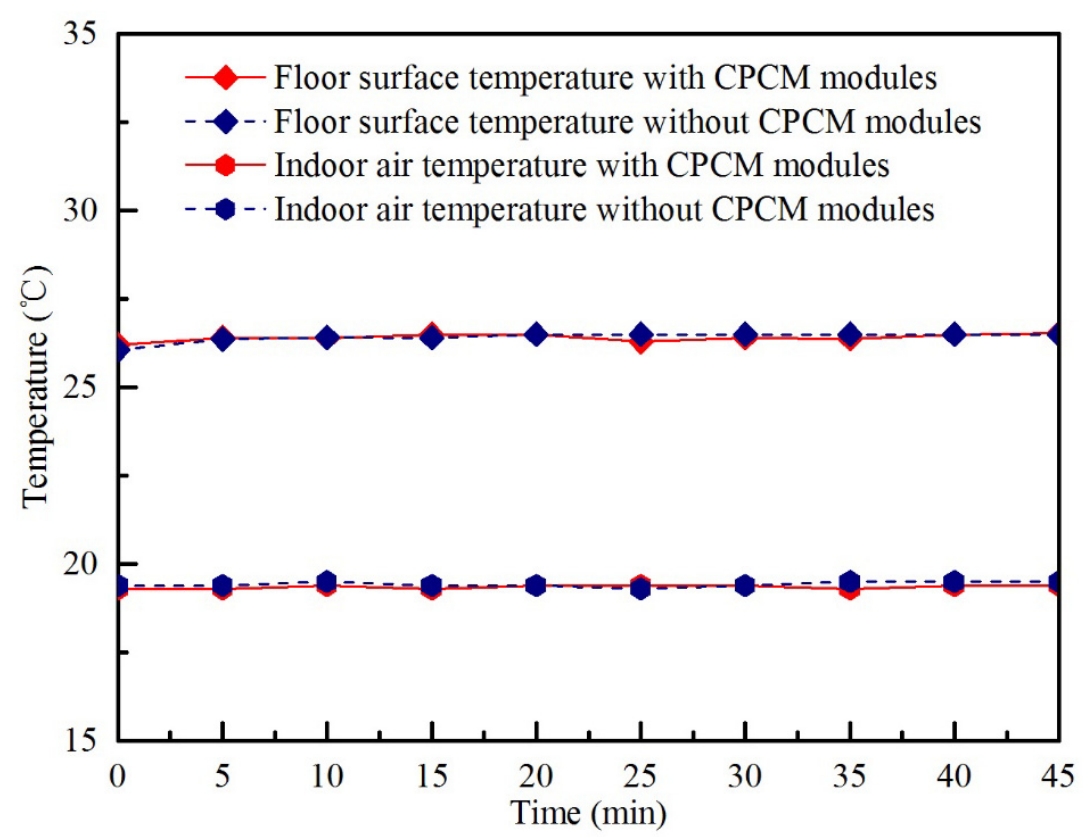

Figure 8. Temperature variations of radiant floor surface and indoor air with and without CPCM modules in the steady state of heating condition.

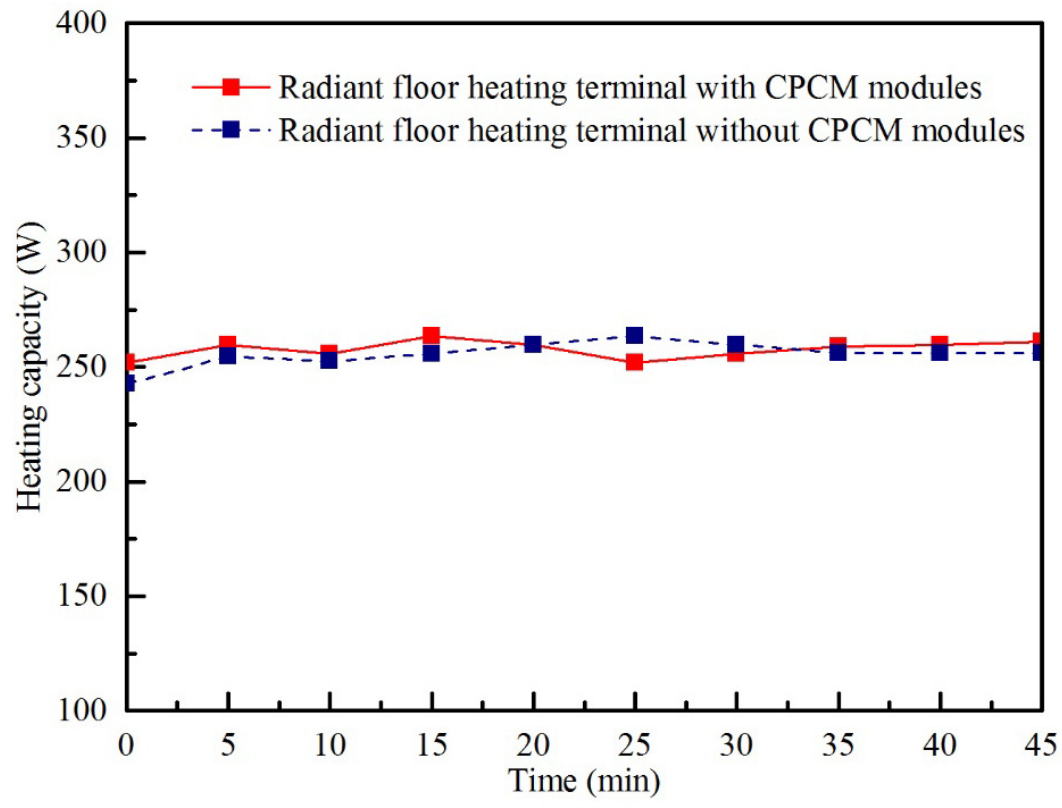

Figure 9. Heating capacity variations of radiant floor heating terminal with and without CPCM modules in the steady state of heating condition.

In addition, the frost occurs on the outdoor unit of the system during the heating condition. The results show that the variations of indoor air temperature and floor surface temperature are very little in the frosting condition. This is because the frost on the finned tube of outdoor unit has an unobvious influence on the air flow and heat-exchange capacity of the outdoor unit due to the relatively short time of frosting condition. As a result, there is little change in the heating capacity transferred to the indoor room which makes a relatively stable indoor air temperature and floor surface temperature in frosting condition. 


\subsection{Thermal Performance of the Experimental System in Defrosting Condition}

Figure 10 shows the temperature variations of the radiant floor surface and indoor air with and without CPCM modules in defrosting period and reheating period. It is observed that both temperatures of the radiant floor surface with and without CPCM modules keep constant at the beginning and then decrease continuously during the defrosting period. Furthermore, the temperature of radiant floor surface with CPCM modules reduces after $6 \mathrm{~min}$, which is $3 \mathrm{~min}$ later than that without CPCM modules. The temperature of radiant floor surface with and without CPCM modules reduced to $25.9^{\circ} \mathrm{C}$ and $24.2^{\circ} \mathrm{C}$ when the defrosting period finished, respectively. After that, both the radiant floor surface temperatures with and without $\mathrm{CPCM}$ modules keep decreasing and then increase during the reheating period. As shown in Figure 10, the temperature variations of indoor air with and without CPCM modules during defrosting condition are similar to those of radiant floor surface. Both the temperature of radiant floor surface and indoor air with CPCM modules are always higher than those without CPCM modules in defrosting condition due to the large latent heat stored in CPCM modules during heating condition.

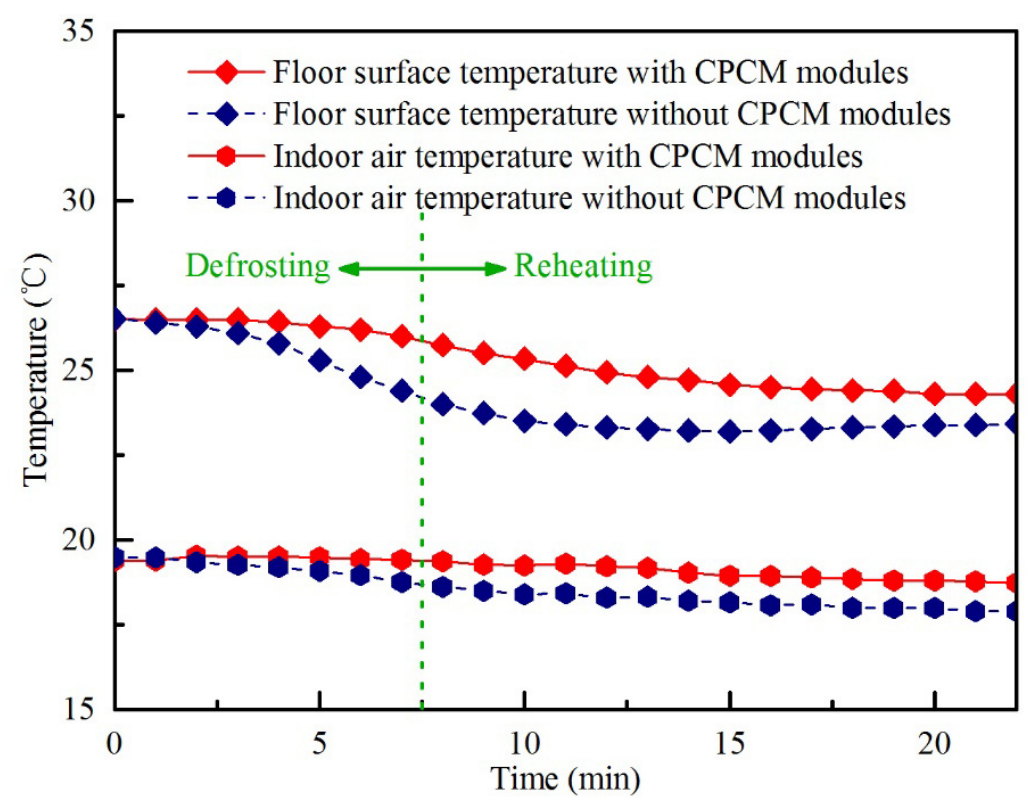

Figure 10. Temperature variations of radiant floor surface and indoor air with and without CPCM modules in defrosting condition.

Figure 11 shows the heating capacity variations of radiant floor heating terminal with and without CPCM modules in defrosting condition. It can be seen that the heating capacity transferred into the room from radiant floor surface without CPCM modules decreases at the beginning, while the radiant floor terminal with CPCM modules maintains a relatively higher heating capacity transferred into the room. The heating capacities transferred into the room from radiant floor surface with and without CPCM modules are $233.3 \mathrm{~W}$ and $195.7 \mathrm{~W}$ at the end of defrosting period, respectively. Compared with heating condition, the heating capacities with and without CPCM modules reduce $11.6 \%$ and $31.5 \%$, respectively. At the same time, the heat flux of radiant floor heating terminal with CPCM modules is $64.6 \mathrm{~W} / \mathrm{m}^{2}$, which is $19.2 \%$ higher than that without CPCM modules. Both the heating capacities transferred into the room from radiant floor surface with and without CPCM modules continue to reduce with the decrease of the radiant floor surface temperature. In addition, the heating capacity transferred into the room from radiant floor surface with CPCM modules is always higher than that without $\mathrm{CPCM}$ modules during defrosting condition. Furthermore, the heat flux of radiant floor terminal with CPCM modules remains more than $50 \mathrm{~W} / \mathrm{m}^{2}$ all the time in defrosting condition. In the defrosting condition, the heating capacity transferred into the room from the radiant floor surface 
with CPCM modules consists of sensible heating capacity and latent heating capacity, while that of the radiant floor surface without $\mathrm{CPCM}$ modules is only sensible heating capacity. The sensible heating capacity of the radiant floor heating terminal without CPCM is higher than that with CPCM due to greater temperature reduction of the former one, and the latent heating capacity of the latter one accounts for more than $70 \%$.

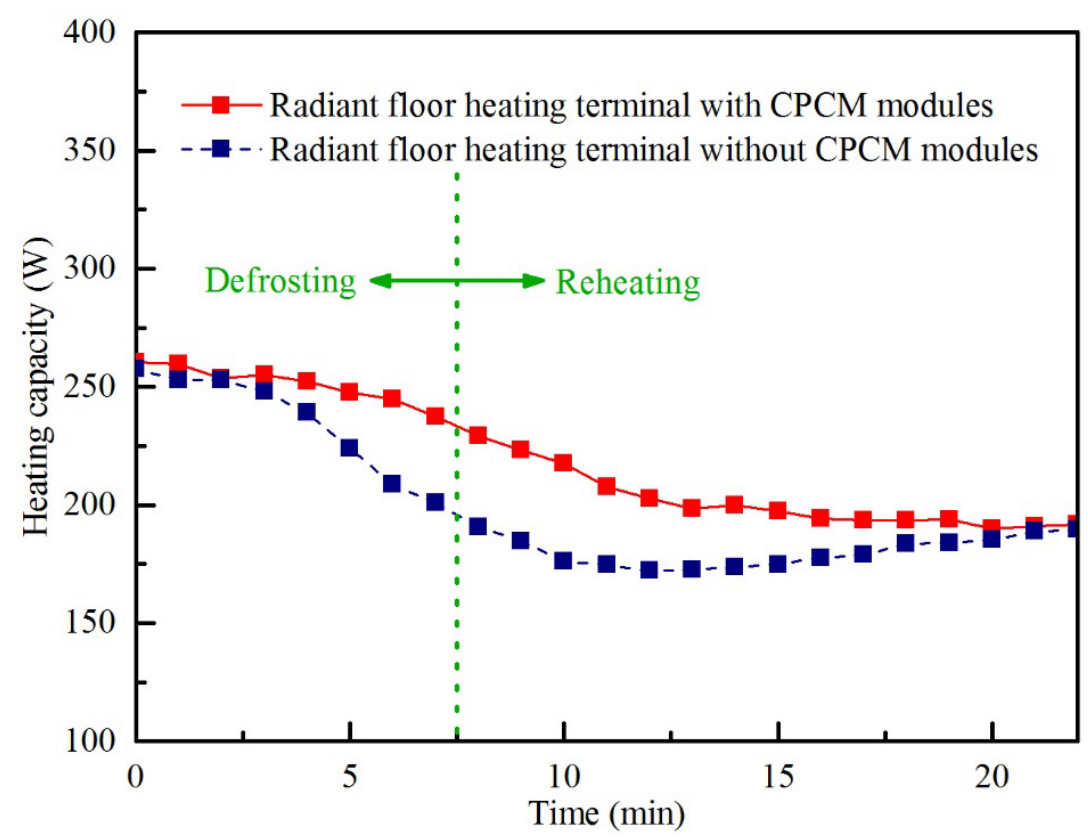

Figure 11. Heating capacity variations of radiant floor heating terminal with and without CPCM modules in defrosting condition.

The variations of the temperature and heating capacity indicate that the heat supplied for defrosting are mainly provided by the heat storage of the CPCM modules in heating condition rather than by the floor and indoor air in the proposed system. The results demonstrate that the indoor thermal environment conditioned by the proposed system maintains a better thermal comfort in defrosting condition with higher heating capacity and less temperature reduction.

\section{Conclusions}

To improve the thermal comfort of the air-source heat pump system and avoid complicating the system, a novel ASHP combined refrigerant direct-condensation radiant floor heating system attached with thermal energy storage is proposed in this study. The characteristics of the dodecanoic acid-tetradecanol-hexadecanol/expanded graphite (LA-TD-HD/EG) composite phase change material $(\mathrm{CPCM})$ and the thermal performance of the proposed system in heating and defrosting conditions are experimentally investigated. The main conclusions are drawn as follows:

1. Considering the thermal conductivity, adsorption completeness, and the latent heat of the LA-TD-HD/EG CPCM, the optimal mass fraction of LA-TD-HD/EG CPCM with EG is determined as $5 \%$.

2. Compared with the mixture without EG, the heat storage and release rate of its LA-TD-HD/EG CPCM can be improved dramatically, supported by the significant reduction of the storage and release time of about $56.4 \%$ and $39.8 \%$, respectively.

3. Compared with the system without CPCM modules, the proposed system with CPCM modules can satisfy the heating requirement with appropriate floor surface temperature and enough heating capacity. The temperature of radiant floor surface and indoor air with and without CPCM modules are higher than $26.0^{\circ} \mathrm{C}$ and $19.0^{\circ} \mathrm{C}$ in this period, respectively. The heating capacity transferred into the room from radiant floor terminal with and without CPCM modules is almost equal to each other. 
4. Compared with the system without CPCM modules, the indoor thermal environment conditioned by the proposed system maintains a higher stability and comfort in defrosting condition with higher heating capacity supplied by the radiant floor heating terminal. Both the temperature of radiant floor surface and indoor air with CPCM modules are always higher than those without CPCM modules in defrosting period and reheating period. The heating capacity transferred into the room from radiant floor surface with CPCM modules is $19.2 \%$ higher than that without CPCM modules at the end of defrosting period. The results indicate that the heat supplied for defrosting is mainly provided by the heat storage of the CPCM modules in heating condition rather than by the floor and indoor air in the proposed system. As a result, the heat flux of the radiant floor terminal with CPCM modules is always more than $50 \mathrm{~W} / \mathrm{m}^{2}$ in whole defrosting condition.

The proposed system with composite phase change material modules is indicated to be able to improve indoor thermal comfort in defrosting condition as well as satisfy the heating requirement in heating condition, which can be applied in severe cold areas. In the near future, the leaking and durability performance of CPCM should be further studied and the structural and thermophysical parameters of the refrigerant direct-condensation radiant floor heating system with composite phase change material should be further optimized.

Author Contributions: Conceptualization, C.Z. and S.Y.; methodology, C.Z., S.Y., and H.Z.; writing—original draft preparation, C.Z.; writing - review and editing, S.Y., W.Z., Z.W., and M.F.; supervision, S.Y. and Z.L. All authors have read and agreed to the published version of the manuscript.

Funding: This research was funded by National Natural Science Foundation of China, grant number 51808386.

Conflicts of Interest: The authors declare no conflict of interest.

\section{Nomenclature}

A

Gr

$H_{j}$

$h_{c}$

$h_{r}$

l

$M_{j}$

$m_{C P C M}$

$m_{P C M}$

$\mathrm{Nu}$

$Q$

$Q_{l}$

$Q_{s}$

$q$

$\operatorname{Pr}$

$R a$

$T_{m}$

$T_{j}$

$t_{a}$

$t_{f}$

$t_{w}$

$X_{i}$

$\delta X_{i}$

$Y$

$\delta Y$

$\triangle H_{C P C M}$

$\triangle H_{P C M}$ surface area, $\mathrm{m}^{2}$

Grashof number

latent heat of the jth component, $\mathrm{kJ} \mathrm{kg}^{-1}$

convective heat transfer coefficient, $\mathrm{W} \mathrm{m}^{-2} \mathrm{~K}^{-1}$

radiant heat transfer coefficient, $\mathrm{W} \mathrm{m}^{-2} \mathrm{~K}^{-1}$

characteristic length, $\mathrm{m}$

molar fraction of the $j$ th component

mass fractions of LA-TD-HD/EG CPCM

mass fractions of LA-TD-HD PCM

Nusselt number

heating capacity, $\mathrm{W}$

latent heating capacity, $\mathrm{W}$

sensible heating capacity, $\mathrm{W}$

heat flux, $\mathrm{W} \mathrm{m}^{-2}$

Prandtl number

Rayleigh number

phase change temperature of the eutectic mixture, ${ }^{\circ} \mathrm{C}$

phase change temperature of the $j$ th Component, ${ }^{\circ} \mathrm{C}$

indoor air temperature, ${ }^{\circ} \mathrm{C}$

radiant floor surface temperature, ${ }^{\circ} \mathrm{C}$

unheated wall surface temperature, ${ }^{\circ} \mathrm{C}$

primary parameter

uncertainty of $X_{i}$

derived quantity

uncertainty of $Y$

latent heats of LA-TD-HD/EG CPCM

latent heats of LA-TD-HD PCM 


\begin{tabular}{|c|c|}
\hline \multicolumn{2}{|c|}{ Greek Symbols } \\
\hline$v$ & kinematic viscosity, $\mathrm{m}^{2} \mathrm{~s}^{-1}$ \\
\hline$\lambda$ & thermal conductivity, $\mathrm{W} \mathrm{m} \mathrm{m}^{-1} \mathrm{~K}^{-1}$ \\
\hline$a$ & thermal diffusivity, $\mathrm{m}^{2} \mathrm{~s}^{-1}$ \\
\hline$\beta$ & coefficient of volumetric expansion, $\mathrm{K}^{-1}$ \\
\hline$\varepsilon$ & emissivity of the radiant floor surface \\
\hline$\sigma$ & Stefan-Boltzmann constant, $5.67 \times 10^{-8} \mathrm{~W} \mathrm{~m}^{-2} \mathrm{~K}^{-4}$ \\
\hline \multicolumn{2}{|c|}{ Abbreviations } \\
\hline ASHP & air-source heat pump \\
\hline CPCM & composite phase change material \\
\hline PCM & phase change material \\
\hline DSC & differential scanning calorimetry \\
\hline EG & expanded graphite \\
\hline HD & hexadecanol \\
\hline LA & dodecanoic acid \\
\hline TD & tetradecanol \\
\hline \multicolumn{2}{|c|}{ Subscripts } \\
\hline $\mathrm{a}$ & air \\
\hline c & connective \\
\hline $\mathrm{f}$ & floor surface \\
\hline $\mathrm{m}$ & eutectic mixture \\
\hline $\mathrm{r}$ & radiant \\
\hline $\mathrm{w}$ & unheated wall \\
\hline
\end{tabular}

\section{References}

1. Hu, W.; Jiang, Y.; Qu, M.; Ni, L.; Yao, Y.; Deng, S. An experimental study on the operating performance of a novel reverse-cycle hot gas defrosting method for air source heat pumps. Appl. Therm. Eng. 2011, 31, 363-369.

2. Zheng, X.; Shi, R.; You, S.; Han, Y.; Shi, K. Experimental study of defrosting control method based on image processing technology for air source heat pumps. Sustain. Cities Soc. 2019, 51, 101667. [CrossRef]

3. Dogru, M.; Nakamura, M.; Shimazaki, J.; Tsubota, K. Changing trends in the treatment of dry-eye disease. Expert Opin. Investig. Drug. 2013, 22, 1581-1601. [CrossRef] [PubMed]

4. Zhu, J.H.; Sun, Y.Y.; Wang, W.; Ge, Y.J.; Li, L.; Liu, J.D. A novel temperature-humidity-time defrosting control method based on a frosting map for air-source heat pump. Int. J. Refrig. 2015, 54, 45-54. [CrossRef]

5. Wang, Z.; Ning, H.; Ji, Y.; Hou, J.; He, Y. Human thermal physiological and psychological responses under different heating environments. J. Therm. Biol. 2015, 52, 177-186. [CrossRef]

6. Zhou, G.; He, J. Thermal performance of a radiant floor heating system with different heat storage materials and heating pipes. Appl. Energy 2015, 138, 648-660. [CrossRef]

7. Maivel, M.; Kurnitski, J. Low temperature radiator heating distribution and emission efficiency in residential buildings. Energy Build. 2014, 69, 224-236. [CrossRef]

8. Zhang, H.; Jiang, L.; Zheng, W.; You, S.; Jiang, T.; Shao, S.; Zhu, X. Experimental study on a novel thermal storage refrigerant-heated radiator coupled with air source heat pump heating system. Build Environ. 2019, 164, 106341. [CrossRef]

9. Zhou, B.; Tan, H.W.; Wang, L. Application study on radiator heating system with air-source heat pump in Shanghai area. Heat. Vent. Air Cond. 2013, 43, 83-87. (In Chinese)

10. Dong, J.K.; Zhang, L.; Deng, S.M.; Yang, B.; Huang, S. An experimental study on a novel radiant-convective heating system based on air source heat pump. Energy Build. 2018, 158, 812-821. [CrossRef]

11. Shao, S.; Zhang, H.; You, S.; Zheng, W.; Jiang, L. Thermal performance analysis of a new refrigerant-heated radiator coupled with air-source heat pump heating system. Appl. Energy 2019, 247, 78-88. [CrossRef]

12. Sebarchievici, C.; Dan, D.; Sarbu, I. Performance Assessment of a Ground-coupled Heat Pump for an Office Room Heating using Radiator or Radiant Floor Heating Systems. Procedia Eng. 2015, 118, 88-100. [CrossRef]

13. Zhang, H. Human Thermal Sensation and Comfort in Transient and Non-uniform Thermal Environments. Ph.D. Thesis, University of California, Berkeley, CA, USA, 2003. 
14. Zeiler, W.; Boxem, G. Effects of thermal activated building systems in schools on thermal comfort in winter. Build. Environ. 2009, 44, 2308-2317. [CrossRef]

15. Sattari, S.; Farhanieh, B. A parametric study on radiant floor heating system performance. Renew. Energy 2006, 31, 1617-1626. [CrossRef]

16. Shin, M.S.; Rhee, K.N.; Ryu, S.R.; Yeo, M.S.; Kim, K.W. Design of radiant floor heating panel in view of floor surface temperatures. Build. Environ. 2015, 92, 559-577. [CrossRef]

17. Li, Q.; Chen, C.; Zhang, Y.; Lin, J.; Ling, H.; Ma, Y. Analytical solution for heat transfer in a multilayer floor of a radiant floor system. Build. Simul. 2014, 7, 207-216. [CrossRef]

18. Xu, D.; Qi, T.; Zhen, L. Energy and exergy analysis of solar integrated air source heat pump for radiant floor heating without water. Energy Build. 2017, 142, 128-138.

19. Amer, M.; Wang, C.C. Review of defrosting methods. Renew. Sustain. Energy Rev. 2017, 73, 53-74. [CrossRef]

20. Shen, J.; Qian, Z.; Xing, Z.; Yu, Y.; Ge, M. A review of the defrosting methods of air source heat pumps using heat exchanger with phase change material. Energy Procedia 2019, 160, 491-498. [CrossRef]

21. Moreno, P.; Solé, C.; Castell, A.; Cabeza, L.F. The use of phase change materials in domestic heat pump and air-conditioning systems for short term storage: A review. Renew. Sustain. Energy Rev. 2014, 39, 1-13. [CrossRef]

22. IEA. Heat Pump Centre Newsletter; IEA: Paris, France, 1990; Volume 8, p. 10.

23. Chen, C.; Yang, J.; Wang, X. New method of heat compensation for defrosting of air source heat pump system in winter. J. Refrig. 2006, 27, 37-40. (In Chinese)

24. Dong, J.; Jiang, Y.; Yao, Y. Experimental study on the characteristics of thermal energy storage for air-source heat pump defrosting using sub-cooling energy of refrigeration. Acta Energ. Sol. Sin 2012, 33, 1536-1540. (In Chinese)

25. Zhang, L.; Dong, J.; Jiang, Y.; Yao, Y. A novel defrosting method using heat energy dissipated by the compressor of an air source heat pump. Appl. Energy 2014, 133, 101-111.

26. Dong, J.; Li, S.; Yao, Y.; Jiang, Y.; Tian, Y.; Tian, H. Defrosting performances of a multi-split air source heat pump with phase change thermal storage. Int. J. Refrig. 2015, 55, 49-59. [CrossRef]

27. Ma, S.; Jiang, Y.; Wen, B. Experimental study on the performance of the ASHP with phase change thermal storage evaporator. Acta Energ. Sol. Sin. 2015, 36, 604-609. (In Chinese)

28. Qu, M.; Li, T.; Deng, S. Improving defrosting performance of cascade air source heat pump using thermal energy storage based reverse cycle defrosting method. Appl. Therm. Eng. 2017, 121, 728-736. [CrossRef]

29. Liu, Z.; Li, A.; Wang, Q. Experimental study on a new type of thermal storage defrosting system for frost-free household refrigerators. Appl. Therm. Eng. 2017, 118, 256-265. [CrossRef]

30. Cabrol, L.; Rowley, P. Towards low carbon homes - a simulation analysis of building-integrated air-source heat pump systems. Energy Build. 2012, 48, 127-136. [CrossRef]

31. Mazo, J.; Delgado, M.; Marin, J.M.; Zalba, B. Modeling a radiant floor system with Phase Change Material (PCM) integrated into a building simulation tool: Analysis of a case study of a floor heating system coupled to a heat pump. Energy Build. 2012, 47, 458-466. [CrossRef]

32. Jin, X.; Zhang, X.S. Thermal analysis of a double layer phase change material floor. Appl. Therm. Eng. 2011, 31, 1576-1581. [CrossRef]

33. Wang, E.; Kong, X.; Rong, X.; Yao, C.; Yang, H.; Qi, C. A Study on a Novel Phase Change Material Panel Based on Tetradecanol/Lauric Acid/Expanded Perlite/Aluminium Powder for Building Heat Storage. Materials 2016, 9, 896. [CrossRef] [PubMed]

34. Zhang, N.; Yuan, Y.; Wang, X.; Cao, X.; Yang, X.; Hu, S. Preparation and characterization of lauric-myristic-palmitic acid ternary eutectic mixtures/expanded graphite composite phase change material for thermal energy storage. Chem. Eng. J. 2013, 231, 214-219. [CrossRef]

35. Yang, X.; Yuan, Y.; Zhang, N.; Cao, X.; Liu, C. Preparation and properties of myristic-palmitic-stearic acid/expanded graphite composites as phase change materials for energy storage. Sol. Energy 2014, 99, 259-266. [CrossRef]

36. Zhao, C.; You, S.; Zhu, C.; Cabeza, L.F. Experimental investigation on the thermal performance of heat storage walls coupled with active solar systems. Heat Mass Transf. 2016, 52, 2747-2757. [CrossRef]

37. JG/T 403, Test Methods of Thermal Performance of Radiant Cooling and Heating Unit; Ministry of Housing and Urban-Rural Development of the People's Republic of China (MOHURD): Beijing, China, 2013. 
38. Liu, M.; Zhang, H.; Zheng, W.; You, S. Heat Transfer Research of a New Type of Radiant Floor Heating System. Heat Transf. Eng. 2020, 41, 1626-1641. [CrossRef]

39. Zhang, L.; Dong, J.; Jiang, Y.; Deng, S.; Huang, S. An experimental study on frosting and defrosting performances of a novel air source heat pump unit with a radiant-convective heating terminal. Energy Build. 2018, 16, 10-21. [CrossRef]

40. ASHRAE. ASHRAE Hand Book-Fundamentals; Chapter 4: Heat transfer; American Society of Heating Refrigeration and Air-conditioning Engineers: Atlanta, GA, USA, 2009.

41. Bejan, A.; Kraus, A.D. Heat Transfer Handbook; John Wily \& Sons, Inc.: Hoboken, NJ, USA, 2003.

42. Lewandowskia, W.M.; Lewandowska-Iwaniak, W. The external walls of a passive building: A classification and description of their thermal and optical properties. Energy Build. 2014, 69, 93-102. [CrossRef]

43. Wu, Z.; You, S.; Zhang, H.; Zheng, W. Experimental investigation on heat transfer characteristics of staggered tube bundle heat exchanger immersed in oscillating flow. Int. J. Heat Mass Transf. 2020, 148, 119-125. [CrossRef]

44. Zhang, N.; Yuan, Y.; Du, Y.; Cao, X.; Yuan, Y. Preparation and properties of palmitic-stearic acid eutectic mixture/expanded graphite composite as phase change material for energy storage. Energy 2014, 78, 950-956. [CrossRef]

45. Wu, Y.; Wang, T. Hydrated salts/expanded graphite composite with high thermal conductivity as a shape-stabilized phase change material for thermal energy storage. Energy Convers. Manag. 2015, 101, 164-171. [CrossRef]

46. Fu, W.; Zou, T.; Liang, X.; Wang, S.; Gao, X.; Zhang, Z.; Fang, Y. Thermal properties and thermal conductivity enhancement of composite phase change material using sodium acetate trihydrate-urea/expanded graphite for radiant floor heating system. Appl. Therm. Eng. 2018, 138, 618-626. [CrossRef]

(C) 2020 by the authors. Licensee MDPI, Basel, Switzerland. This article is an open access article distributed under the terms and conditions of the Creative Commons Attribution (CC BY) license (http://creativecommons.org/licenses/by/4.0/). 